\section{Evaluation of Management Programs for Protecting Young Citrus Plantings from Huanglongbing}

\author{
David G. Hall ${ }^{1}$, Tim R. Gottwald, and Ed Stover \\ USDA-ARS Horticultural Research Laboratory, 2001 S. Rock Road, Fort \\ Pierce, FL, 34945
}

G. Andrew C. Beattie

School of Science and Health, University of Western Sydney, Locked Bag 1797, Penrith, New South Wales 2751, Australia

Additional index words. Asian citrus psyllid, Diaphorina citri, citrus greening

\begin{abstract}
Asiatic huanglongbing (HLB) is a devastating disease of citrus associated in North America with the bacterium 'Candidatus Liberibacter asiaticus' (LAS) vectored by the Asian citrus psyllid (ACP), Diaphorina citri Kuwayama. ACP management is considered a vital component of a program aimed at reducing the incidence and spread of HLB. Considerable research has been published comparing the efficacy of different insecticides for ACP control as well as on seasonal strategies for applying ACP insecticides. However, published information was largely lacking for even the most intense insecticide programs on their effectiveness for keeping HLB out of a new citrus planting in Florida citrus. We therefore conducted two replicated (individual plots 0.2 to 0.4 ha in size) experiments on protecting young citrus from HLB using different ACP management programs. An intensive insecticide program was evaluated in each experiment: eight annual calendar applications of traditional insecticides (hereafter referred to as the "complete" program). In one experiment, citrus was either planted alone and subjected to the complete program or citrus was interplanted with orange jasmine, Murraya exotica L. (a favored ACP host plant) and subjected to a reduced insecticide program (four calendar sprays of traditional insecticides). There was one set of plots in which both jasmine and citrus were treated with insecticides and one set in which jasmine was not treated at all. In the second experiment, citrus was either subjected to the complete program or to one of two other programs: a reduced insecticide program consisting of five calendar applications of traditional insecticides or a mineral oil program (oil applications every 3 weeks plus one dormant insecticide spray). The results of the two experiments were similar. Relatively good ACP control was achieved under each ACP management program during the first year but, as the experiments progressed and trees increased in size, ACP outbreaks occurred regardless of the psyllid management program. Little HLB developed under any ACP management program during the first year, but thereafter HLB increased and large percentages of the trees in each experiment became LAS-infected in less than two to three years. The combined results of the experiments indicated that up to eight monthly pesticide treatments per year applied on a calendar schedule were ineffective for preventing young citrus from becoming diseased. Of important significance is that the orchard within which the two experiments were conducted was subjected to a minimal psyllid management program and contained many older trees known to be infected by the HLB pathogen, a challenging situation for getting young trees into production without contracting the disease. Thus, the ACP management programs we evaluated might have been more effective if $\mathrm{ACP}$ in the surrounding areas had been more aggressively controlled and diseased trees in the surrounding areas removed to reduce inoculum loads. Also, the programs might have been more effective for slowing the spread of HLB if our research plots had been larger.
\end{abstract}

Huanglongbing is considered one of the most serious diseases of citrus (Gottwald, 2007). Also known as citrus greening or yellow shoot disease, HLB is caused by bacteria within the genus 'Candidatus Liberibacter' (Bové, 2006). In the United States and many other areas around the world, huanglongbing is associated with LAS and is vectored by the ACP, Diaphorina citri Kuwayama (Hemiptera: Psyllidae). Trees infected by LAS often develop a distinctly thinned canopy, decline significantly in productivity, may produce misshapen off-flavored fruit, and ultimately may
Stansly, 2007, 2010; Rogers, 2008). Insecticides such as imidacloprid, fenpropathrin, chlorpyrifos, thiamethoxam, and dimethoate are regarded as effective against ACP and are registered for citrus in Florida (Rogers et al., 2012a). Initial response to HLB in Florida was largely concerned with maintaining the health and productivity of existing trees. However, replanting young trees is essential to sustain a citrus industry (Spreen, 2012), and little information was available on effectiveness of insecticidal control of ACP on consequent introduction and spread of the HLB pathogen in new plantings.

Presented here are the results of two experiments conducted to assess epidemiology of HLB in new plantings of citrus subjected to different ACP management programs. In one experiment, orange jasmine [Murraya exotica L. = Murraya paniculata auct. non. (USDA-ARS-NGRP, 2012)] interplanted with citrus was investigated as a supplemental management tactic for reducing ACP infestations and HLB in citrus. Orange jasmine is a favored ACP host plant (Westbrook et al., 2011), and we were interested in whether this plant might be useful as a biofilter to detour ACP from citrus or to enhance biological control of ACP. In the second experiment, a program of repetitive applications of horticultural mineral oils was compared with routine applications of traditional insecticides for reducing ACP infestations and HLB. In each experiment, a seasonal ACP control program consisting of eight annual calendar applications of traditional insecticides (hereafter referred to as the "complete" program) was evaluated as a baseline for treatment comparisons.

\section{Materials and Methods}

In each of the two experiments, young citrus trees were planted at a USDA-ARS citrus orchard near the city of Fort Pierce in Saint Lucie County in east-central Florida (lat. $27^{\circ} 26^{\prime} 8.46^{\prime \prime} \mathrm{N}$, long. $-80^{\circ} 25^{\prime} 51.31^{\prime \prime} \mathrm{W}$ ) at $5.8 \mathrm{~m}$ (19 feet) above sea level. The trees for the experiments were purchased from a citrus nursery operating under State of Florida compliance agreements for the production of HLB-free trees. For general research purposes at the orchard where the experiments were conducted, a majority of existing trees were subjected to minimal ACP control and many surrounding trees were known to be infected by the HLB pathogen (probably more than $75 \%$ ). The experiments were therefore in the midst of high ACP and LAS inoculum pressure. Table 1 presents a list of the specific insecticides and mineral oils we investigated during the two experiments.

Expt. 1: Interplanting orange jasmine with citrus. Three management programs (Table 2) were compared for protecting a new planting of citrus from ACP and HLB: 1) citrus planted alone and subjected to eight annual insecticide treatments reflecting maximal use of materials effective against ACP and sequenced to reduce development of resistant insects (the "complete" insecticide program); 2) citrus 
interplanted with orange jasmine with citrus subjected to a reduced insecticide program and orange jasmine not treated with insecticides; and 3) citrus interplanted with orange jasmine with citrus subjected to the same reduced insecticide program and orange jasmine regularly treated with insecticides. Foliar insecticides were applied in $280 \mathrm{~L} \cdot \mathrm{ha}^{-1}$ (30 gal/acre) of spray the first year and thereafter in $467 \mathrm{~L} \cdot \mathrm{ha}^{-1}$ (50 gal/acre) using a highpressure handgun sprayer. For insecticides applied in combination with mineral oil, 435 Soluble Oil was used. Imidacloprid was applied using fertigation as described in Table 2 using half of the maximum legal rate in Year 1 and the full legal rate thereafter.

The trees studied in this experiment were 'Valencia' sweet orange [Citrus sinensis (L.) Osbeck] on 'Cleopatra' mandarin (Citrus reshni hort. ex Tanaka) rootstock and were

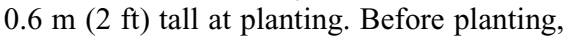
each tree was confirmed to be free of LAS using molecular assays described below. Orange jasmine plants growing in $3.8-\mathrm{L}$ (1 gal) pots were purchased from a local nursery and were $0.3 \mathrm{~m}(1 \mathrm{ft})$ tall when they were planted. These plants were not tested for the HLB pathogen. The citrus and jasmine were planted during May 2008. Individual plots were $\approx 0.2$ ha $(0.5$ acres $)$ in size and consisted of seven rows, 16 trees per row with $3.0-\mathrm{m}(10 \mathrm{ft})$ tree spacing for a total of 544 trees/ha (220 trees per acre). For plots with citrus interplanted with orange jasmine, a jasmine plant was interplanted between each citrus plant along Rows 1, 4, and 7 with one jasmine plant at each end of each of the seven rows. Three replications of each program were studied (randomized block design).

All trees in the experiment were subjected to a uniform nutritional program, which we regarded as fairly traditional for Florida citrus. Granular fertilizer $(12 \mathrm{~N}-2 \mathrm{P}-14 \mathrm{~K})$ was applied at $448 \mathrm{~kg} \cdot \mathrm{ha}^{-1}$ (400 lbs/acre) annually during the first year and thereafter at 896 $\mathrm{kg} \cdot \mathrm{ha}^{-1}$ (800 lbs/acre) annually. Part of the nitrogen component of this fertilizer was from pasteurized poultry litter, which provided slower release rates of nitrogen and additional organic matter. Also, a total of $11 \mathrm{~kg} \cdot \mathrm{ha}^{-1}$ $(10 \mathrm{lbs} /$ acre $)$ of nitrogen $(\mathrm{N})$ and potassium (K) was applied to leaves each year in

Received for publication 13 Dec. 2012. Accepted for publication 18 Jan. 2013.

Funding for this project was provided by the Citrus Research and Development Foundation.

Mention of a trademark or proprietary product is solely for the purpose of providing specific information and does not constitute a guarantee or warranty of the product by the U.S. Department of Agriculture and does not imply its approval to the exclusion of other products that may also be suitable.

We thank the following individuals for their contributions to this research: Monty Watson, Matt Hentz, Kathy Moulton, Joanne Hodge, Kyle Berk, Ashley Voss, Lindsay Shaffer, Steve Mayo (all USDA-ARS), Michael Fefer (Petro-Canada), and Pete Spyke (Arapaho Citrus Management, Inc., Fort Pierce, FL). ${ }^{1}$ To whom reprint requests should be addressed; e-mail David.Hall@ars.usda.gov.

Table 1. Insecticides and mineral oils used during the experiments on managing Asian citrus psyllid.

\begin{tabular}{|c|c|c|}
\hline Chemical name (percent active ingredient) & Brand name & Manufacturer \\
\hline 435 mineral oil $(99 \%)^{z}$ & $\begin{array}{l}\text { Diamond R Brand } 435 \\
\text { Soluble Oil }\end{array}$ & $\begin{array}{l}\text { Diamond R Fertilizer Co., } \\
\text { Inc. (Ft. Pierce, FL) }\end{array}$ \\
\hline 435 mineral oil $(99 \%)^{y}$ & PureSpray Green & $\begin{array}{l}\text { Petro-Canada (Mississauga, } \\
\text { Ontario, Canada) }\end{array}$ \\
\hline 470 mineral oil $(99 \%)^{\mathrm{x}}$ & PureSpray Foliar 22E & $\begin{array}{l}\text { Petro-Canada (Mississauga, } \\
\text { Ontario, Canada) }\end{array}$ \\
\hline Zeta-cypermethrin $(9.6 \%)$ & Mustang & Bayer CropScience (NC) \\
\hline Imidacloprid $(42.8 \%)$ & Admire Pro & Bayer CropScience (NC) \\
\hline Abamectin $(2 \%)$ & Agri-Mek 0.15EC & Syngenta (Greensboro, NC) \\
\hline Chlorpyrifos $(44.9 \%)$ & Lorsban 4E & $\begin{array}{l}\text { Dow AgroSciences } \\
\text { (Indianapolis, IN) }\end{array}$ \\
\hline Carbaryl (44.1\%) & Sevin XLR Plus & Bayer CropScience (NC) \\
\hline Dimethoate $(44.8 \%)$ & Dimethoate 4EC & $\begin{array}{l}\text { Helena Chemical Company } \\
\text { (Collierville, TN) }\end{array}$ \\
\hline Fenpropathrin $(30.9 \%)$ & Danitol 2.4EC Spray & $\begin{array}{l}\text { Valent U.S.A. Corporation } \\
\text { (Walnut Creek, CA) }\end{array}$ \\
\hline
\end{tabular}

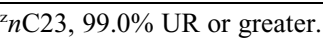

${ }^{\mathrm{y}} \mathrm{nC} 23,92.0 \% \mathrm{UR}$ or greater.

${ }^{x} n \mathrm{C} 27,99.0 \%$ UR or greater.

Table 2. Management programs evaluated for protecting young citrus from Asian citrus psyllid and huanglongbing: assessing potential of interplanting orange jasmine (Expt. 1). ${ }^{\mathrm{z}}$

\begin{tabular}{llc}
\hline Target date & \multicolumn{1}{c}{ Insecticide treatment } & Rate $\left(\mathrm{L} \cdot h a^{-1}\right)(\mathrm{fl} \mathrm{oz} /$ acre $)$ \\
\hline Program 1: Citrus & monoculture, complete insecticide program \\
15 Feb. & Zeta-cypermethrin & $0.32(4.3)$ \\
$15 \mathrm{Apr}$. & Imidacloprid (soil applied) & $0.52(7.0)^{\mathrm{y}}$ \\
1 June & Abamectin with oil (2\% v/v) & $0.74(10.0)$ \\
$15 \mathrm{July}$ & Imidacloprid (soil applied) & $0.52(7.0)^{\mathrm{y}}$ \\
$15 \mathrm{Aug}$. & Chlorpyrifos with oil $(2 \% \mathrm{v} / \mathrm{v})$ & $5.85(80.0)$ \\
$15 \mathrm{Sept}$ & Carbaryl with oil $(2 \% \mathrm{v} / \mathrm{v})$ & $3.51(48.0)$ \\
$15 \mathrm{Nov}$. & Dimethoate & $1.16(16.0)$ \\
$15 \mathrm{Dec}$. & Fenpropathrin & $1.16(16.0)$
\end{tabular}

Program 2: Citrus planted with orange jasmine, with a reduced insecticide program for citrus and jasmine not treated with insecticides
$15 \mathrm{Apr}$.
1 June
Imidacloprid (soil applied)
$0.52(7.0)^{\mathrm{y}}$
15 July
Abamectin with oil $(2 \% \mathrm{v} / \mathrm{v})$
$0.74(10.0)$
15 Aug.
Imidacloprid (soil applied)
$0.52(7.0)^{y}$
$5.85(80.0)$

Program 3: Citrus planted with orange jasmine, with a reduced insecticide program for citrus and jasmine treated with insecticides
1 Feb.
15 Apr.
Jasmine-imidacloprid (soil applied)
$0.52(7.0)^{\mathrm{x}}$
Citrus-imidacloprid (soil applied)
$0.52(7.0)^{\mathrm{y}}$
1 June
Citrus and jasmine-abamectin with oil ( $2 \% \mathrm{v} / \mathrm{v})$
15 July
Citrus and jasmine-imidacloprid (soil applied)
$0.74(10.0)$
$0.52(7.0)^{\mathrm{y}, \mathrm{x}}$
15 Aug.
Citrus and jasmine-chlorpyrifos with oil $(2 \% \mathrm{v} / \mathrm{v})$
$5.85(80.0)$
Jasmine-fenpropathrin
$1.16(16.0)$

${ }^{2}$ All insecticides applied as a foliar treatment except imidacloprid, which was applied by fertigation. ${ }^{\mathrm{y}}$ During Year $1 \mathrm{of}$ the experiment, imidacloprid was applied to citrus at $0.25 \mathrm{~L} \cdot \mathrm{ha}^{-1}$ ( $3.3 \mathrm{fl} \mathrm{oz} / \mathrm{acre}$ )

${ }^{x}$ During Year 1 of the experiment, jasmine was treated with a granular formulation of imidacloprid (Bayer Feed and Protect; Bayer CropScience, NC) twice a year at the maximum label rate and thereafter with soil drenches of imidacloprid at the same rate applied to citrus.

combination with either Keyplex 1400 DP (KeyPlex, Winter Park, FL) or RTRx Plus (Diamond R Fertilizer Co., Fort Pierce, FL) at label rates. In addition to these nutritional treatments, the trees were treated three or four times during the summer with copper sulfate pentahydrate (Magna-Bon CS2005; Magna-Bon II, LLC, Okeechobee, FL) or copper hydroxide (Kocide 2000; E. I. du Pont de Nemours and Company, Wilmington, DE) at label rates to control foliar diseases of citrus.

Populations of the psyllid were monitored in each plot using yellow sticky traps $(8 \times$ $13 \mathrm{~cm}$; Great Lakes IPM, Vestaburg, MI) as described by Hall et al. (2010). Traps (one per tree) were deployed in 11 citrus trees near the center of each plot along Rows 3, 4, and 5. In the plots with orange jasmine, traps (one per plant) were deployed in three orange jasmine plants near the center of each plot along Row 4. A 2-week trapping period was followed for the entire study. With respect to natural enemies, adult coccinellids collected on sticky traps were counted. Incidence of trees infected by LAS in each plot was followed for 3.5 years using molecular procedures described below, with four surveys each year. Initially, leaves from five successive trees along a row were collected and analyzed as a composite sample using molecular procedures described below. Each tree was then tested individually if the composite sample was positive for LAS. Within 3 to 4 weeks of identifying infected 
trees, they were removed from the plots and not replaced. This sometimes required that sticky traps be deployed in different trees.

Expt. 2: Conventional insecticides versus mineral oils. Three management programs (Table 3) were evaluated for protecting a new planting of citrus from ACP and HLB: 1) citrus subjected to the previously mentioned "complete" insecticide program; 2) citrus subjected to a reduced insecticide program; and 3) citrus subjected to an intensive horticultural mineral oil program. There were two plots (replications) of each treatment. For the oil program, two different oils were evaluated, PureSpray Green (PSGreen) and PureSpray Foliar 22E (PSFoliar), and each was applied to runoff as a $0.6 \% \mathrm{vol} / \mathrm{vol}$ spray in water. The two oils differed with respect to carbon numbers (Table 1) and thus evaporation rates. As a result of space limitations, half of the rows of each plot subjected to the oil program were treated with PSGreen and the other half were treated with PSFoliar. In addition to oil, this program included one winter application of fenpropathrin. For all foliar treatments, $280 \mathrm{~L} \cdot \mathrm{ha}^{-1}$ (30 gal/acre) of spray was applied the first year and thereafter $467 \mathrm{~L} \cdot \mathrm{ha}^{-1}$ (50 gal/acre) using a high-pressure handgun sprayer. For insecticides applied in combination with mineral oil, 435 Soluble Oil was used. Imidacloprid was applied using fertigation as described in Table 2 using half of the maximum legal rate in Year 1 and the full legal rate thereafter.

Young 'Valencia' trees on the rootstock 'Carrizo' citrange [Poncirus trifoliata (L.) Raf. $\times$ Citrus sinensis (L.) Osbeck] were planted during Summer 2009 when the trees

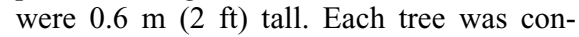
firmed to be free of LAS through polymerase chain reaction assay before planting. The planting site was bedded with two rows per bed. Individual plots of trees for the experiment were 0.36 ha ( 0.9 acres) in size and consisted of eight rows with 27 trees per row and 2.4-m $(8.0 \mathrm{ft})$ tree spacing along rows for a total of 620 trees/ha (250 trees per acre).

All trees in this experiment were uniformly subjected to the same annual nutritional program, which differed from Expt. 1 and used pulse-fertigation nutrient and water management currently being explored for higher-density plantings of Florida citrus (Schumann et al., 2009). Liquid fertilizer, $20 \mathrm{~N}-10 \mathrm{P}-20 \mathrm{~K}$, was applied (fertigated) through an irrigation system at $504 \mathrm{~kg} \cdot \mathrm{ha}^{-1}$ (450 lbs/acre) annually with $0.15 \%$ magnesium; another liquid fertilizer, $15 \mathrm{~N}-5 \mathrm{P}-15 \mathrm{~K}$, was applied through the irrigation system at $93 \mathrm{~kg} \cdot \mathrm{ha}^{-1}$ (83 lbs/acre) annually and included $4 \%$ calcium and $2 \%$ magnesium along with minor elements. The bulk of these liquid fertilizers was applied during the spring, summer, and fall by fertigating a stock solution of $34 \mathrm{~kg}(75 \mathrm{lb})$ of material in $662 \mathrm{~L}(175$ gal) of water, $10-\mathrm{min}$ pulses nine times a day at $1.5 \mathrm{~L}(0.4 \mathrm{gal})$ per minute. Early during the winter the stock solution was reduced to $23 \mathrm{~kg} / 662 \mathrm{~L}$ (50 lb/175 gal) for 1 week and then to $11 \mathrm{~kg} / 662 \mathrm{~L}(25 \mathrm{lb} / 175 \mathrm{gal})$ for 1 week, after which there were 6 weeks in the middle of winter in which no fertigation was conducted. As spring approached, the amount of material added to the tank was increased to $11 \mathrm{~kg}(25 \mathrm{lb})$ and then to $23 \mathrm{~kg}(50 \mathrm{lb})$ each for 1 week before returning to the full stock solution. In addition to these soil-applied liquid fertilizers, $11 \mathrm{~kg} \cdot \mathrm{ha}^{-1}$ (10 lbs/acre) of $\mathrm{N}$ and $\mathrm{K}$ were applied to leaves each year in combination with either Keyplex 1400 DP or RTRx Plus at label rates. In addition to nutritional treatments, the trees were treated three or four times during the summer with copper sulfate pentahydrate (Magna-Bon CS2005) or copper hydroxide (Kocide 2000) at label rates to control foliar diseases of citrus.

Table 3. Insecticide programs evaluated for protecting young citrus from Asian citrus psyllid and huanglongbing: comparison of complete and reduced insecticide programs to intensive mineral oil sprays (Expt. 2). ${ }^{\mathrm{z}}$

\begin{tabular}{|c|c|c|}
\hline Target date & Insecticide treatment & Rate $\left(\mathrm{L} \cdot \mathrm{ha}^{-1}\right)(\mathrm{fl} \mathrm{oz} /$ \\
\hline \multicolumn{3}{|c|}{ Program 1: Complete insecticide program } \\
\hline 15 Feb. & Zeta-cypermethrin & $0.32(4.3)$ \\
\hline 15 Apr. & Imidacloprid (soil applied) & $0.52(7.0)^{\mathrm{y}}$ \\
\hline 1 June & Abamectin with oil $(2 \% \mathrm{v} / \mathrm{v})$ & $0.74(10.0)$ \\
\hline 15 July & Imidacloprid (soil applied) & $0.52(7.0)^{\mathrm{y}}$ \\
\hline 15 Aug. & Chlorpyrifos with oil $(2 \% \mathrm{v} / \mathrm{v})$ & $5.85(80.0)$ \\
\hline 15 Sept. & Carbaryl with oil $(2 \% \mathrm{v} / \mathrm{v})$ & $3.51(48.0)$ \\
\hline 15 Nov. & Dimethoate & $1.16(16.0)$ \\
\hline 15 Dec. & Fenpropathrin & $1.16(16.0)$ \\
\hline
\end{tabular}

Program 2: Reduced insecticide program

$\begin{array}{lll}15 \text { Apr. } & \text { Imidacloprid (soil applied) } & 0.52(7.0)^{\mathrm{y}} \\ 1 \text { June } & \text { Abamectin with oil }(2 \% \mathrm{v} / \mathrm{v}) & 0.74(10.0) \\ 15 \mathrm{July} & \text { Imidacloprid (soil applied) } & 0.52(7.0)^{\mathrm{y}} \\ 15 \text { Aug. } & \text { Chlorpyrifos with oil }(2 \% \mathrm{v} / \mathrm{v}) & 5.85(80.0) \\ 15 \mathrm{Dec} . & \text { Fenpropathrin } & 1.16(16.0)\end{array}$

Program 3: Mineral oil program

15 Feb. to Applications every 3 weeks (14 total)

15 Nov. Fenpropathrin

$2.82(38.4)^{\mathrm{x}}$

$1.16(16.0)$

${ }^{\mathrm{z}}$ All insecticides applied as a foliar treatment except imidacloprid, which was applied by fertigation.

${ }^{y}$ During Year 1 of the experiment, imidacloprid applied at $0.25 \mathrm{~L} \cdot \mathrm{ha}^{-1}$ ( $3.3 \mathrm{fl} \mathrm{oz} /$ acre $)$.

${ }^{\mathrm{x}}$ Applied as a $0.6 \%$ solution to runoff.
Infestation levels of adult psyllids in each plot were monitored every 3 weeks by counting the total number of adults on a pair of mature leaves including the stem between them (Hall et al., 2008). Five pairs of leaves were examined on each of 40 arbitrarily selected trees in each plot. For plots under the oil treatment, 40 trees were sampled along rows under the PSFoliar treatment and 40 were sampled along rows under the PSGreen treatment. Infestations of psyllids were further investigated by sampling one flush shoot on each of the 40 trees every 3 weeks; the number of adults per flush shoot was counted, and whether eggs or nymphs were present was recorded. Lastly, adult populations in the plots were monitored using yellow sticky traps (described previously). One trap per tree was hung in each of nine trees uniformly positioned within the interior two rows of each plot (five tree buffer between a tree with a trap and the last tree along a row). For plots under the oil program, nine trees with traps were monitored along rows under the PSFoliar treatment and nine were monitored along rows under the PSGreen treatment. Traps were deployed and retrieved on a 3-week schedule.

The trees were monitored every three months for HLB (composite tree samples like in Expt. 1) using molecular procedures described below. Trees identified as infected were left in place and treated as if they were not diseased, receiving the same irrigation and nutritional programs as healthy trees.

Molecular assays for LAS. Only citrus trees grown in a disease-free enclosed nursery and confirmed to be free of LAS (using the assay procedures presented here) were planted in this experiment. After planting, the trees were sampled for LAS once every three months. Trees infected by LAS were identified using quantitative polymerase chain reaction (qPCR) primers and protocols developed by Li et al. (2006). Briefly, two to four leaves with petioles were detached from two or more major tree branches (leaves with probable HLB symptoms were preferentially chosen). DNA was extracted from the midrib/ petiole of the sampled leaves. For each tree, a combined sample of 100 to $180 \mathrm{mg}$ of midrib was excised before DNA extraction. After extraction, total nucleic acids in each sample was quantified using a nano-drop spectrophotometer (Nanodrop 1000; Thermo Scientific, USA) and standardized to 25 $\mathrm{ng} \cdot \mu \mathrm{L}^{-1}$ with nuclease-free sterile water. The quantitative TaqMan PCR method uses $16 \mathrm{~S}$ rDNA-based primer-probe sets specific to LAS. The primer/probe system employed was labeled with NED/MGB, i.e., it uses a TaqMan minor groove binding probe, which incorporates a $5^{\prime}$ reporter dye and a $3^{\prime}$ nonflourescent quencher. The reporter dye used was NED. This system was optimal for use on the real-time PCR instrument with a FAST platform (Applied Biosystems, Life Technologies Corporation, Carlsbad, CA). Invitrogen Express qPCR Master Mix was used with the addition of the primers, probe, nuclease-free water, and polyvinylpyrrolidone (PVP). The 
primers were used at a concentration of $0.3 \mu \mathrm{M}$, the probe at $0.15 \mu \mathrm{M}$, and the PVP (added to bind PCR reaction inhibitors) at $25 \mathrm{mg} \cdot \mathrm{mL}^{-1}$ mix. Total volume per each of the 96 wells/plate was $20 \mu \mathrm{L}$.

The cycle parameters of the real-time program were: $95{ }^{\circ} \mathrm{C}$ for $20 \mathrm{~s}$ followed by 40 cycles of $95^{\circ} \mathrm{C}$ for $3 \mathrm{~s}$ and $60^{\circ} \mathrm{C}$ for $30 \mathrm{~s}$. The instrument software (ABI software; International Trade Systems, Portland, OR) calculates a noise baseline from fluorescent background in the early cycles of the PCR reaction, whereas the signal from target amplification is negligible. A threshold value is then automatically calculated indicating a statistically significant point above the background noise and data for a sample is reported as threshold cycle $(\mathrm{Ct})$ value, which is the number of PCR cycles necessary to reach significant sample signal. Lower Ct values indicate higher initial template in the well, requiring fewer amplification cycles to reach the threshold of significance. For our studies, we considered a $\mathrm{Ct}$ value of less than 32 as positive for the pathogen.

Statistical analyses. For each experiment, data means \pm SEM were computed using PROC MEANS; analyses of variance were conducted using PROC ANOVA; and regression analyses were conducted using PROC GLM (all procedures by SAS Institute, Inc., 2010). Multiple comparisons among data means were made using the $F$-protected Tukey's Studentized range test. Percentage data were arcsine-transformed (Gomez and Gomez, 1984) for statistical analyses. An average area under curve analysis (Madden et al., 2007) was conducted for each experiment to compare ACP management programs with respect to increases in percentages of infected trees. All evaluations of statistical significance were conducted at $P=0.05$.

\section{Results}

Expt. 1: Interplanting orange jasmine with citrus. Few adult ACPs were captured on yellow sticky traps deployed in citrus trees during the first year of the experiment regardless of the ACP management program (Fig. 1A-B). Greater numbers of ACP were collected during Summer 2009 in plots of citrus interplanted with jasmine when the latter was not treated with insecticides. Overall sample periods, a mean \pm SEM number of $0.4 \pm 0.1$ ACP per trap was captured in plots under the complete insecticide program. Under the reduced insecticide program for citrus interplanted with jasmine, $1.4 \pm 0.4$ ACPs per trap were trapped in citrus in plots where jasmine was treated with insecticides and $4.7 \pm 0.2$ ACPs per trap was trapped in citrus where jasmine was not treated with pesticides. Overall sample periods, psyllids were most abundant in jasmine not treated with insecticides (12.3 \pm 2.9 ACPs per trap) and moderately abundant in jasmine treated with insecticides (2.4 \pm 0.7 ACPs per trap). Adult lady beetles (including species known to prey on ACP) were relatively abundant in jasmine plants (Fig. 1C) whether jasmine was treated
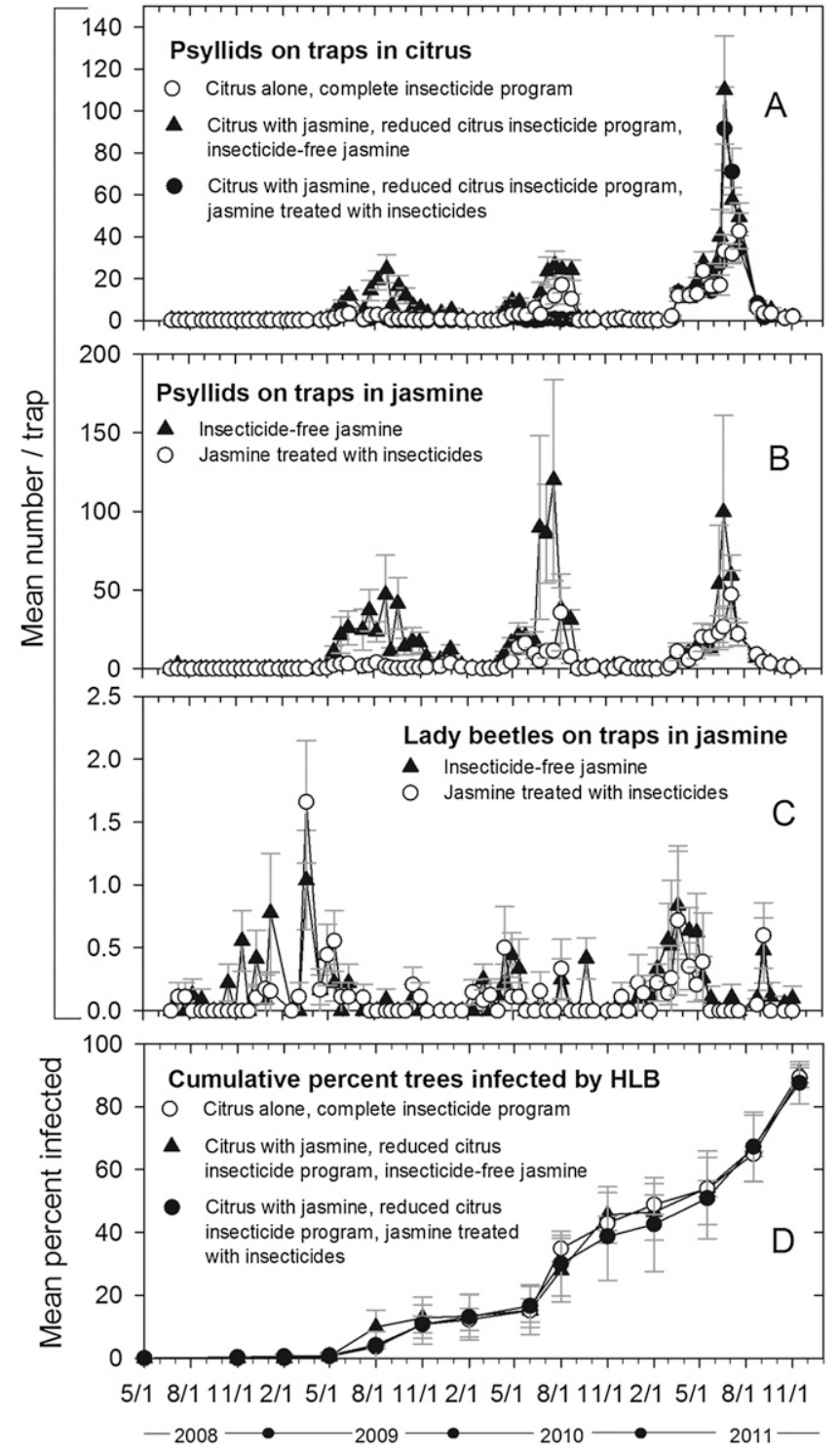

Fig. 1. A comparison of three different management programs for Asian citrus psyllid and huanglongbing (HLB) in young citrus trees planted during May 2008 (Expt. 1, evaluating different insecticide programs in citrus planted alone or in citrus interplanted with orange jasmine). Citrus trees were screened for the HLB pathogen every three months and those that tested positive were removed and not replaced. (A) Mean number of psyllids per trap deployed in citrus trees. (B) Mean number of psyllids per trap deployed in orange jasmine. (C) Mean number of lady beetles per trap deployed in orange jasmine. (D) Cumulative percentages of citrus trees testing positive for the HLB bacterium. Error bars are SEM.

with insecticide $(0.11 \pm 0.03$ beetles per trap) or not treated $(0.13 \pm 0.03$ beetles per trap). Compared with numbers of beetles trapped in jasmine, numbers trapped in citrus were similar: $0.08 \pm 0.02$ per trap under the complete program; $0.16 \pm 0.04$ per trap under Program 2; and $0.11 \pm 0.02$ per trap under Program 3.

Less than $1 \%$ of the trees under each ACP management program tested positive for the HLB pathogen at 12 months after planting, but by Aug. 2010 (27 months after planting), the percentage of trees infected by the pathogen under the three programs ranged from $28 \%$ to $35 \%$ (Fig. 1D). By Feb. 2011 across all three programs, an average of $45.9 \%$ of the trees in each plot had become infected and removed, and by Nov. 2011, across all three programs, an average of $90 \%$ of the trees had become infected. The area under the curve (AUC) analysis indicated no significant difference among the three ACP management programs with respect to increases in HLB over time $\left(F_{2,4}=0.02, P=0.98\right)$. Based on an analysis overall three treatments on average percentages of trees infected on each sample date, simple linear regression indicated that the percentage of infected trees $(Y)$ was related to number of days after planting $(X): Y=-18.9+0.067 X ; F_{1,40}=253, P=<$ $0.0001, r^{2}=0.86$. The SE of the slope was 0.004 .

Expt. 2: Conventional insecticides versus mineral oils. Populations of adult ACP were scarce in the young trees for nine to 10 months after planting regardless of the $\mathrm{ACP}$ 


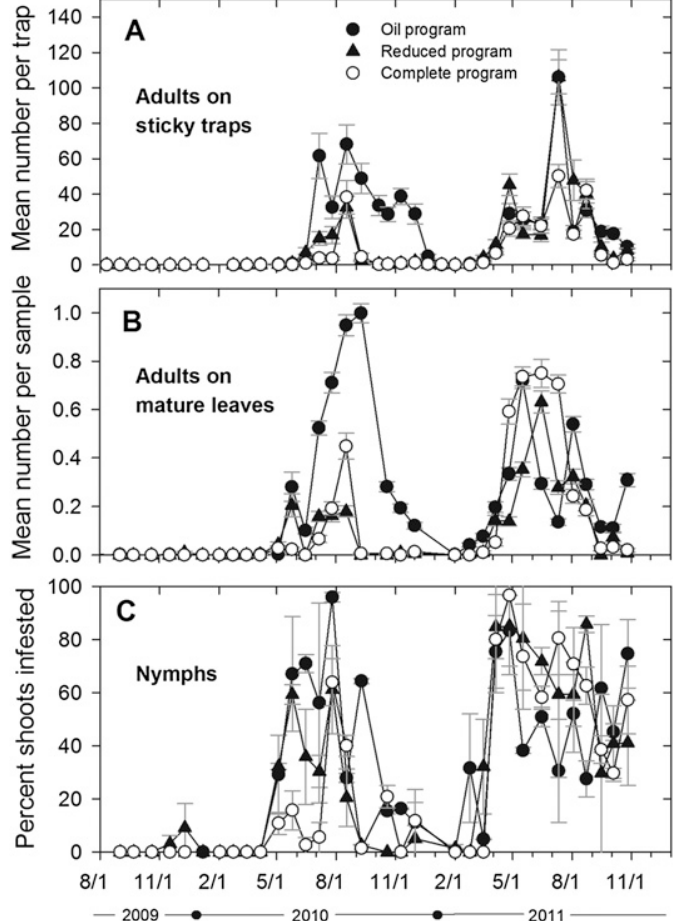

Fig. 2. A comparison of three different management programs for Asian citrus psyllid in young citrus trees planted Summer 2009 (Expt. 2, evaluating traditional insecticide and oil programs). (A) Mean number of psyllids per trap. (B) Mean number of psyllids per pair of mature leaves. (C) Mean percentages of flush shoots infested by psyllid nymphs. Error bars are SEM.

control program (Fig. 2A-B). Thereafter in trees under the oil program, adult population levels increased and remained generally abundant. During the last six months of the experiment, adults were generally abundant regardless of the ACP program. Low percentages of flush shoots were found to be infested by ACP nymphs in trees under the reduced insecticide program within the first four to five months after planting (Fig. 2C). Large percentages of flush shoots were sometimes infested by nymphs during 2010, especially in trees under the oil program, and during 2011, large percentages of shoots were often infested by nymphs regardless of the ACP program.

A mean \pm SEM number of $18 \pm 3,11 \pm 3$, and $7 \pm 2$ adult ACPs per sticky trap was observed overall sample dates in plots under the oil, reduced insecticide, and complete programs, respectively, with maximums of 118,116 , and 54 per trap, respectively. A mean \pm SEM number of $0.20 \pm 0.05,0.08 \pm$ 0.03 , and $0.12 \pm 0.04$ ACPs per pair of mature leaves was observed overall sample dates in plots under the oil, reduced insecticide, and complete programs, respectively. There was no significant difference among these means $\left(F_{2,2}=2.6, P=0.1\right)$. Overall sample dates, a mean of $0.59 \pm 0.10,0.65 \pm 0.15$, and $0.56 \pm$ 0.15 adult ACPs per flush shoot was observed in plots under the oil, reduced insecticide, and complete programs, respectively. There was no significant difference among these means $\left(F_{2,2}=0.7, P=0.5\right)$. Overall sample dates, a mean \pm SEM of $41.7 \% \pm 4.8 \%, 29.4 \% \pm$ $4.4 \%$, and $27.0 \% \pm 5.1 \%$ shoots were infested by psyllids (all life stages combined) in plots under the oil, reduced insecticide, and complete programs, respectively. There were no significant differences between percentages of flush shoots infested under the oil and reduced insecticide programs, but these percentages were significantly higher than in plots under the complete program $\left(F_{2,2}=5.2\right.$, $P=0.01$; Tukey's test).

No phytotoxicity (leaf soaking, leaf drop, or retarded growth) was observed in trees treated with the mineral oils. Population levels over time of ACP in plots of trees regularly treated with PSGreen mineral oil were generally similar to those in plots of trees regularly treated with PSFoliar based on numbers of ACP collected on sticky traps and also on percentages of flush shoots infested by nymphs (data not presented). Overall sample dates, means \pm SEM of $19.4 \pm 3.2$ and $16.7 \pm 2.9$ adults per sticky trap were observed in trees treated with PSFoliar and PSGreen, respectively; there was no significant difference between these means $(t=-0.63, P>|t|=0.53,142 \mathrm{df})$. Also overall sample dates, $29.9 \% \pm 4.8 \%$ and $30.1 \% \pm 5.3 \%$ flush shoots were infested by nymphs in trees treated with PSFoliar and PSGreen, respectively; these means were not significantly different $(t=-0.06, P>$ $|t|=0.95,138 \mathrm{df}$ ). Numbers of adults observed on mature leaves from nine to 15 months after planting were generally lower in trees treated with PSFoliar (data not presented), but overall sample dates, there was no significant difference between the two mineral oils with respect to numbers of
ACP on mature leaves $(t=-0.37, P>|t|=$ $0.71,138 \mathrm{df}$ ).

Few trees were identified as being infected by the HLB pathogen at five months after planting (Fig. 3A). By July 2010 (11 months after the experiment began), overall three treatments, there was a mean \pm SEM of $10 \% \pm 3 \%$ trees infected. Thereafter, percentages of trees identified as being LAS-infected steadily increased and, although fewer trees were generally infected under the complete program at approximately one year and half after planting, by Oct. $2011,99.5 \% \pm 0.5 \%$ of the trees were infected regardless of the ACP program. These trends in increases of HLB over time were generally the same regardless of whether trees were treated with the PSFoliar or PSGreen oil program (Fig. 3B). The AUC analysis indicated no significant difference among the three ACP management programs with respect to increases in HLB over time $\left(F_{2,2}=0.53, P=0.66\right)$. Based on an analysis overall three treatments on average percentages of trees infected on each sample date, simple linear regression indicated that the percentage of infected trees $(Y)$ was related to number of days after planting $(X)$ : $Y=-14.7+0.129 X ; F_{1,22}=188, P=<0.0001$, $r^{2}=0.90$. Based on the SE of the slope (0.009), trees developed HLB at a faster rate in Expt. 2 than in Expt. 1.

Greater than $99 \%$ of the trees under each ACP program were alive during Oct. 2010 ( $\approx 14$ months after the experiment began). By 19 Jan. 2011 (17 months after the experiment began), from $3.0 \%$ to $4.6 \%$ of the trees appeared to be dead, attributed largely to hard freezes during Dec. 2010. Among 50 trees that were completely defoliated by these freezes and appeared to be dead, a mean \pm SEM of $14 \% \pm 28 \%$ had been identified as LAS-infected before the freezes. Subsequently during Jan. 2011, these trees could not be sampled for HLB. Percentages of infected trees were therefore based on the number of trees that could be sampled.

On 14 Apr. 2011, there was a mean of $3.9 \% \pm 3.9 \%, 3.5 \% \pm 3.5 \%$, and $8.6 \% \pm 0.2 \%$ trees dead in plots under the oil, reduced insecticide, and complete programs, respectively. There were no significant differences among these percentages $\left(F_{2,2}=0.5, P=0.7\right)$. Among a total of 91 trees that died by Apr. $2011,20.9 \%$ had been identified as LASinfected.

\section{Discussion}

Few ACPs were observed in citrus during the first year after planting in Expt. 1 under each of the three ACP management programs; however, as the experiment progressed and trees increased in size, ACP outbreaks periodically occurred regardless of the psyllid management program but especially in plots of citrus interplanted with insecticide-free jasmine. The presence of orange jasmine with citrus failed to enhance ACP control in citrus regardless of whether jasmine was treated with insecticides or not. Psyllids were more abundant in jasmine not 


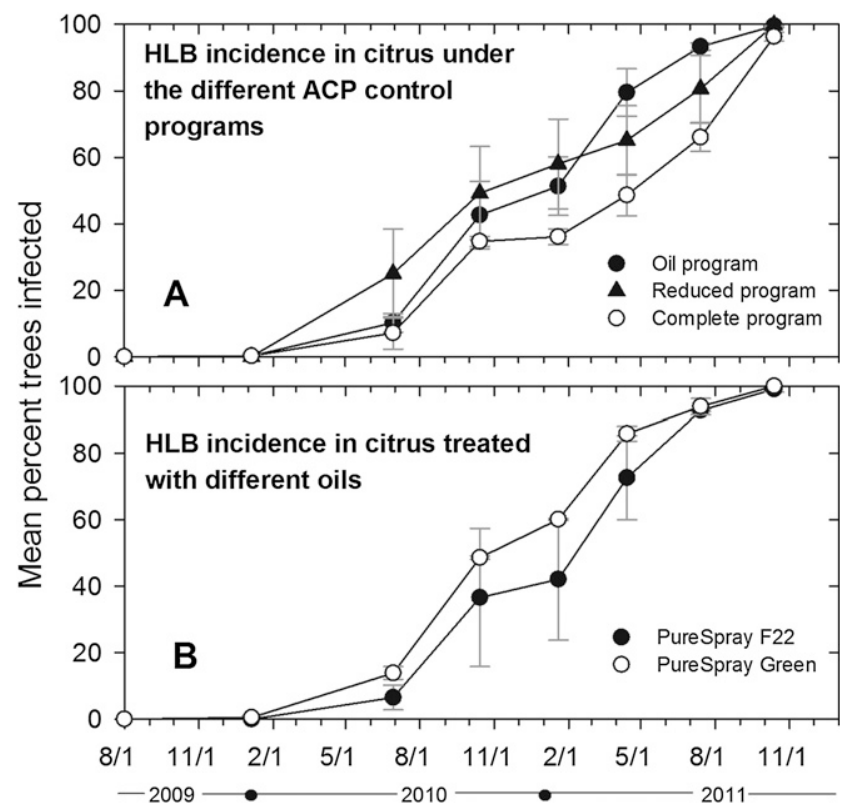

Fig. 3. Cumulative percentages of citrus trees testing positive for the huanglongbing (HLB) pathogen (Expt. 2, evaluating traditional insecticide and oil programs). Trees were screened for the bacterium every three months, and those that tested positive were left in the field. (A) Comparison of HLB in trees subjected to three different Asian citrus psyllid (ACP) management programs. (B) Comparison of HLB in citrus trees subjected to two different horticultural mineral oil programs (together they constitute the oil program in A). Error bars are SEM.

treated with insecticides than in jasmine treated with insecticides. Lady beetles were relatively abundant in jasmine plants whether jasmine was treated or not treated with pesticide, and numbers of beetles observed in citrus were similar to those observed in jasmine. We did not make assessments of the presence of other ACP biological control agents. However, based on numbers of ACP observed on traps, biological control agents associated with orange jasmine not treated with insecticides did not promote any measurable reductions in ACP in either citrus or jasmine (nor ultimately on the incidence of HLB). Few trees became LAS-positive under any program during the first 12 to 15 months, but thereafter the incidence of infected trees increased and at 42 months after planting, $\approx 90 \%$ of the trees had become infected regardless of the psyllid program. It remained possible that better ACP control and a reduction in the incidence and spread of HLB might have been seen in citrus planted with jasmine had these jasmine plants been larger in size when the citrus was planted (particularly under Program 3). On the other hand under Program 2, larger jasmine plants might have harbored greater numbers of ACP, which could have increased spread of HLB. Noted was that several freezes early during the experiment caused considerable damage to the young jasmine plants, which set back jasmine's growth progress.

Similar to the results of the first experiment, few ACPs were observed in citrus during the first year after planting during Expt. 2 under each of the ACP management programs but, as the experiment progressed and trees increased in size, ACP outbreaks occurred regardless of the psyllid management program, but especially in plots under the oil program. In retrospect, the interval between oil sprays was probably too long, particularly during periods when the trees produced flush. Leong et al. (2012) reported that weekly or fortnightly applications of $n \mathrm{C} 24$ oil (as determined by scouting with a zero tolerance threshold) usually at $0.5 \%$ $(\mathrm{v} / \mathrm{v})$ were as effective as synthetic insecticides from suppressing ACP on flush. In our study, few trees became LAS-positive under any program during the first year of Expt. 2, but thereafter infection increased and at 26 months after planting nearly $100 \%$ of the trees had detectable HLB pathogen regardless of the psyllid management program. Increases in percentages of HLB-infected trees tended to be slower in citrus under the PSFoliar mineral oil program than under the PSGreen program (Fig. 3B). PSFoliar is a heavier oil $(n \mathrm{C} 27)$ and thus can persist longer as a result of slower volatilization from leaf surfaces and slower movement into plant tissues (Beattie, 2005).

Disease progression was faster in Expt. 2 than Expt. 1. This may have been the result of diseased trees being removed as they were found in Expt. 1 but not in Expt. 2. However, because the initial finding of HLB at this farm occurred only two years before Expt. 1 was planted, and Expt. 2 was planted more than one year after Expt. 1, this difference may simply reflect a farm-wide increase in pathogen inoculum level over the duration of the reported experiments. An average of 5\% trees died within 17 months after planting but only $\approx 1 \%$ of these dead trees were known to be LAS-infected.
The combined results of the two experiments indicated that up to eight monthly pesticide treatments per year applied on a calendar schedule to reduce ACP infestations were insufficient to protect young citrus from infection by LAS. Of important significance is that the orchard within which the two experiments were conducted was subjected to a minimal psyllid management program and contained many older trees known to be infected by LAS; thus, the ACP management programs we evaluated might have been more effective if ACP in the surrounding areas had been more aggressively controlled and diseased trees removed to reduce inoculum loads. It is possible that better ACP control in the young trees could have been achieved under the complete program if it had included a scouting component (either as a substitute for timing sprays on calendar dates or for determining if additional insecticide sprays were needed), but how costly this might be and to what extent an ACP control program based on scouting might help slow HLB progress would need to be investigated. Beattie and Barkley (2009) recommended that an ACP management program be based not on pest abundance but rather on host plant phenology; application of mineral oils or synthetic insecticides would be initiated as flush begins to develop (buds begin opening) and continued as needed until flush is no longer suitable for oviposition, with zero tolerance for any ACP.

In each of the two experiments, newly planted citrus largely remained free of ACP infestations for the first several months after planting regardless of the psyllid management program. Other researchers have reported that ACP may be slow to find and infest new young citrus plants (for example, Ichinose et al., 2012; Leong et al., 2012). A newly planted tree may be too small for ACP to recognize visually as a host plant or may produce insufficient plant volatiles that attract ACP. Data collected during the second experiment indicated that for the first four or five months after planting while the trees were small, adult ACPs were usually not detected using sticky traps or by examining mature leaves. However, examination of flush revealed low populations were present at least in trees under the reduced insecticide treatment. Visual searches may be superior to other ACP detection methods, especially if flush is available (Hall et al., 2012). Regardless of the psyllid management program we studied, ACP outbreaks gradually started occurring as the trees increased in size, with most ACP outbreaks occurring during the summer months as previously noted (Hall et al., 2008). Relatively good psyllid control was achieved under the complete insecticide program in both experiments for the first one to two years, whereas poorer ACP control was generally achieved by each of the other programs during this time period. However, the complete program was relatively ineffective during the last year or two of each experiment.

Based on the results of the two experiments, planting new citrus trees and protecting them 
from HLB is difficult in Florida, particularly if HLB is endemic in the area surrounding a new planting and psyllids are not well controlled in the surrounding area. Other researchers have investigated various $\mathrm{ACP}$ management programs for reducing HLB in citrus but with negative results. In Malaysia, for example, Leong et al. (2012) treated young citrus weekly with horticultural mineral oils, or every other week with conventional pesticides, and regardless of the program, more than $30 \%$ tested positive for the disease pathogen within $\approx 31$ months. These researchers reported that only $\approx 10 \%$ of young trees developed HLB when they were treated with foliar applications of imidacloprid, but the trees were treated every other week (26 times annually). A study in Brazil indicated that there was no relationship between the number of insecticide sprays per year and numbers of trees developing HLB; removing infected trees was more important than applying insecticides for maintaining low incidence of the disease (Berhamin-Filho et al., 2009). These researchers also reported that insecticide sprays within a single planting were not effective for preventing HLB when nearby citrus harbored LAS and infected psyllids.

When citrus trees were removed as they were found and not replaced (Expt. 1), 40\% to $50 \%$ trees had been removed by 33 months after planting and the plots began to look barren. Had the infected trees been replaced with resets, we speculated that resets might have been slow to attract ACP but that eventually they would begin developing the disease at a rate equal to the older young trees. The success and profitability associated with establishing a new planting, protecting it from ACP, and resetting diseased trees as they are found remain to be investigated.

In summary, none of the ACP management programs we investigated completely negated ACP infestations and consequently none circumvented the introduction and spread of HLB among young trees during the first two to three years after planting. As already noted, the programs studied might have been more effective for managing HLB had the young plantings not been surrounded by citrus under minimal ACP/HLB management practices. The importance of area-wide efforts to manage ACP/HLB has been stated before (Xu et al., 1991, as cited by Beattie and Barkley, 2009) and is supported by the recent formation in Florida of Citrus Health Management Areas within which growers band together to treat large acreages of citrus at the same time (Rogers et al., 2012b). Regional studies on HLB management in Brazil have determined that areas of 2000 ha or more must be treated simultaneously to effectively control ACP and hence HLB (R. Bassanezi, personal communication). Future research efforts to manage ACP with insecticides in Florida could evaluate applying insecticides more frequently over the growing season with an increased emphasis on using systemic insecticides as suggested by Rogers (2012). However, additional insecticides with new modes of action would be needed to circumvent the development of resistance to insecticides, because ACP already has developed some insecticide resistance (Tiwari et al., 2011). Young trees would need to be scouted between treatments and additional treatments made when necessary. To this end, a database of the relative efficacy of a number of insecticides against ACP has been developed (Stanlsy et al., 2012). Even if such a program effectively reduced ACP and prevented large percentages of trees from becoming diseased over the first four to six years after planting, the costs could be unsustainable and the intensive program would be disruptive to management programs already in place for other arthropod pests. As an alternative/supplement to an intensive insecticide program, methods could be investigated for keeping young, diseased citrus as healthy as possible to get them into production. This might be accomplished using HLB therapeutics such as heat treatments (Hoffman et al., 2013) or antibiotics (e.g., Zhang et al., 2011) in combination with an optimal young tree nutrition program and other best citrus practices. Ultimately it is hoped that young trees with resistance or tolerance to ACP and LAS can be developed, which would reduce the need for intensive ACP management.

\section{Literature Cited}

Beattie, A. 2005. Using petroleum-based spray oils in citrus. New South Wales Department of Primary Industries, AgFact H2.AE.5.

Beattie, G.A.C. and P. Barkley. 2009. Huanglongbing and its vectors. A pest specific contingency plan for the citrus and nursery and garden industries (Version 2), Feb. 2009. Horticulture Australia, Ltd., Sydney, Australia.

Berhamin-Filho, A., M.C.G. Gasparoto, R.B. Bassanezi, and L. Amorim. 2009. Relationship between insecticide sprays and huanglongbing progress in a citrus orchard in São Paulo, Brazil. Proc. of the International Research Conference on Huanglongbing, Orlando, FL. Dec. 2008. $<\mathrm{http}$ ://www.plantmanagementnetwork.org/ proceedings/irchlb/2008/presentations/IRCHLB. 10.1.pdf $>$.

Bové, J.M. 2006. Huanglongbing: A destructive, newly-emerging, century-old disease of citrus. J. Plant Pathol. 88:7-37.

Gomez, K.A. and A.A. Gomez. 1984. Statistical Procedures for Agricultural Research. 2nd edition. John Wiley \& Sons, New York. 680 pp.

Gottwald, T.R. 2007. Citrus canker and citrus huanglongbing, two exotic bacterial diseases threatening the citrus industries of the Western Hemisphere. Outlooks on Pest Management 18:274-279.

Gottwald, T.R. 2010. Current epidemiological understanding of citrus huanglongbing. Annu. Rev. Phytophathol. 119-139.

Hall, D.G. and T.R. Gottwald. 2011. Pest management practices aimed at curtailing citrus huanglongbing disease. Outlooks on Pest Management 22:189-192.

Hall, D.G., M.G. Hentz, and R.C. Adair. 2008 Population ecology and phenology of Diaphorina citri in two Florida citrus groves. Environ. Entomol. 37:914-924.

Hall, D.G., M.L. Richardson, E.-D. Ammar, and S.E. Halbert. 2012. Asian citrus psyllid, Diaphorina citri (Hemiptera: Psyllidae), vector of citrus huanglongbing disease. Entomol. Exp. Appl. 146:207-223.

Hall, D.G., M. Sétamou, and R.F. Mizell. 2010. A comparison of sticky traps for monitoring Asian citrus psyllid (Diaphorina citri Kuwayama). Crop Prot. 29:1341-1346.

Hoffman, M.T., M.S. Doud, L. Williams, M Zhang, F. Ding, E. Stover, D.G. Hall, S. Zhang, L. Jones, M. Gooch, L. Fleites, W. Dixon, D. Gabriel, and Y.P. Duan. 2013. Heat treatment eliminates 'Candidatus Liberibacter asiaticus' from infected citrus trees under controlled conditions. Phytopahtology 103:15-22.

Ichinose, K., V.H. Nguyen, V.B. Doan, H.T. Do, and Q.D. Le. 2012. Limited efficacy of guava interplanting on citrus greening disease: Effectiveness of protection against disease invasion breaks down after one year. Crop Prot. 34:119-126.

Leong, S.C.T., F. Abang, A. Beattie, R.J.H. Kueh, and S.K. Wong. 2012. Impacts of horticultural mineral oils and two insecticide practices on population fluctuation of Diaphorina citri and spread of huanglongbing in a citrus orchard in Sarawak. The Scientific World Journal 2012. Article ID 651416. doi:10.1100/2012/651416.

Li, W., J.S. Hartung, and L. Levy. 2006. Quantitative real-time PCR for detection and identification of Candidatus Liberibacter species associated with citrus huanglongbing. J. Microbiol. Methods 6:104-115.

Madden, L.V., G. Hughes, and F. van den Bosch. 2007. Temporal analysis I: quantifying and comparing epidemics. In: The study of plant disease epidemics. American Phytopathological Society Press, St. Paul, MN.

Qureshi, J.A. and P.A. Stansly. 2007. Integrated approaches for managing the Asian citrus psyllid Diaphorina citri (Homoptera: Psyllidae) in Florida. Proc. Florida State Hort. Soc. 120:110-115.

Qureshi, J.A. and P.A. Stansly. 2010. Dormant season foliar sprays of broad-spectrum insecticides: An effective component of integrated management for Diaphorina citri (Hemiptera: Psyllidae) in citrus orchards. Crop Prot. 29:860-866.

Rogers, M.E. 2008. General pest management considerations-Responses to greening and its vectors have modified pest management programs. Citrus Industry 89:12-17.

Rogers, M.E. 2012. Protection of young trees from the Asian citrus psyllid and HLB. Citrus Industry $93: 10-15$.

Rogers, M.E., P.A. Stansly, and L.L. Stelinski. 2012a. Florida citrus pest management guide: Asian citrus psyllid and citrus leafminer. University of Florida IFAS Extension Publication ENY-734.

Rogers, M.E., G. Carlton, and T.D. Riley. 2012b. Results from the 'CHMA ACP monitoring' program. Citrus Industry 93:12-16.

SAS Institute, Inc. 2010. Statistical analysis system, version 9.3. SAS Institute, Cary, NC.

Schumann, A.W., J.P. Syvertsen, and K.T. Morgan. 2009. Implementing advanced citrus production systems in Florida-Early results. Proc. Fla. State Hort. Soc. 122:108-113.

Spreen, T.H. 2012. That shrinking feeling. Florida Grower 105:22.

Stanlsy, P., J. Qureshi, and B. Kostyk. 2012. Effectiveness ranking for insecticides against Asian citrus psyllid. Citrus Industry 93:6-9.

Tiwari, S., R.S. Mann, M.E. Rogers, and L.L. Stelinski. 2011. Insecticide resistance in field populations of Asian citrus psyllid in Florida. Pest Mgt. Sci. 67:1258-1268.

USDA-ARS-NGRP. 2012. Germplasm Resources Information Network (GRIN) [online database]. 
National Germplasm Resources Laboratory, Beltsville, MD. 13 Dec. 2012. <http://www.arsgrin.gov/cgi-bin/npgs/html/taxon.pl?24702>.

Westbrook, C.J., D.G. Hall, E.W. Stover, Y.P. Duan, and R.F. Lee. 2011. Susceptibility of Citrus and Citrus-related germplasm to Diaphorina citri (Hemiptera: Psyllidae). HortScience 46:997-1005.
Xu, C.F., D.X. Wang, and C. Ke. 1991. A report of implementation of integrated control of citrus huanglungbin, aiming at renovating old infected orchard in epidemic zone and protecting new noninfected orchard in non-epidemic zone, p. 55-61. In: Ke, C. and S.B. Osman (eds.). Proc. of the Sixth International Asia Pacific Workshop on Integrated Citrus Health
Management, Kuala Lumpur, Malaysia, 24-30 June 1991.

Zhang, M., C. Powell, L. Zhou, Z. He, E.W. Stover, and Y. Duan. 2011. A new combination of antibiotics effective against the citrus huanglongbing bacterium, 'Candidatus Liberibacter asiaticus'. Phytophathology 11: 1097. 